\title{
Financial Crisis Early Warning Based on Panel Data and Dynamic Dual Choice Model
}

\author{
Qingyu Du \\ Faculty of Finance, City University of Macau, Taipa 999078, Macau \\ Correspondence should be addressed to Qingyu Du; f18092105021@cityu.mo
}

Received 20 February 2021; Revised 29 March 2021; Accepted 7 April 2021; Published 17 April 2021

Academic Editor: Wei Wang

Copyright (C) 2021 Qingyu Du. This is an open access article distributed under the Creative Commons Attribution License, which permits unrestricted use, distribution, and reproduction in any medium, provided the original work is properly cited.

\begin{abstract}
Based on the research of currency crisis pressure index, bank crisis pressure index, and asset bubble crisis pressure index, this paper introduces an external shock pressure index reflecting the impact of global economic changes on economy and synthesizes systemic financial crisis pressure based on the above four pressure indexes; then, all the alternative early warning indicators and the systemic risk pressure index constructed in this paper were tested for Granger causality. We build financial systemic risk pressure indexes, including currency crisis pressure (CCP) banking crisis pressure (BCP) index, bubble crisis pressure (PBP) index, and external shock pressure (ESP) index to predict financial crises. Finally, four indicators that have a significant impact on the systemic financial crisis pressure index were selected, namely, the stock price index change rate, industrial added value growth rate, domestic and foreign real deposit interest rate differential, and foreign direct investment as a percentage of GDP. A dynamic Logit model with lagging binary variables is constructed, and compared with the traditional static Logit line, the actual dynamic fitting effect is better than the static Logit model. The dynamic Logit model is used to predict the early warning status of systemic financial crisis in 2020, and the forecast of various early warning indicators is realized by the ARIMA model. The final prediction results show that the probability of a systemic financial crisis in China in 2020 is extremely low, almost zero. This is in line with the overall improvement in the international economic situation in 2020 and the steady growth of the domestic economy.
\end{abstract}

\section{Introduction}

Financial crisis early warning is called the early warning system. Before disasters and other dangers that need to be watched occur, they send emergency signals to relevant departments according to the laws summarized in the past or the possible precursors obtained by observations. The act of reporting dangerous situations in order to prevent the harm from happening without knowing or lack of preparation, thereby minimizing the loss caused by the harm, is the early warning. The term "early warning" was first commonly used in the military and environmental monitoring fields. The earliest application in the economic and financial fields was in 1979 [1]. Padhan and Prabheesh used advanced indicators to study currency crises and pioneered the study of financial crisis early warning. At present, the definition of financial crisis early warning generally agreed by domestic and foreign scholars is as follows: "Financial crisis early warning refers to the construction and analysis of financial early warning indicator system around economic cyclical fluctuations through the application of certain statistical measurement methods. The purpose is to predict the possibility of a financial crisis in a certain country or region within a certain period of time before the occurrence of a financial crisis and to provide decision-makers with a basis for monitoring and preventing financial crises, so as to avoid the destructive effect of the financial crisis on the country or region's economic development" [2].

In the context of the international financial crisis, the market competition among enterprises has become increasingly fierce. The number of listed companies with abnormal financial conditions or other abnormal conditions in China is increasing year by year, whether from the perspective of preventing corporate financial risks or from the perspective of promoting healthy and stable economic development [3]. Early warning of financial distress of listed 
companies is of great significance. In the related research on financial early warning, three main issues are mainly involved: (1) the establishment of financial early warning indicator system, (2) the use of financial prewarning model, and (3) selection of sample data. With regard to the establishment of a financial early warning indicator system, with the continuous deepening of research, scholars have shifted their focus from only focusing on financial indicators to nonfinancial indicators, such as equity concentration [4], audit opinions, and company growth rate. Traditionally, the definition and supervision of systemic risks have been carried out at the microlevel, that is, microprudential supervision, which requires individual financial institution risks to be under control. It is believed that as long as individual risks are effectively prevented and resolved, the system can be controlled as well as the prevention of sexual risks. Microprudential supervision emphasizes the external attributes of systemic risk-causing factors, and the outbreak of the financial crisis exposed the defects of microprudential supervision. Governments and financial institutions in various countries have greatly changed their understanding of systemic risk, and they have begun to emphasize its endogenousness: the collective actions of financial institutions affect the real economy by influencing asset prices, and the real economy uses a feedback mechanism to influence the real economy. The financial system is counterproductive. The 2007-2009 financial crisis showed that a single financial market subject which is in a state of controllable risk does not mean that the overall financial system is also at a healthy level. The consistent behavior of all financial institutions in responding to the economic situation is bound to accumulate a large number of asset bubbles, and the burst of the bubble will eventually trigger a financial crisis. Therefore, the current supervision of systemic financial risks has gradually shifted from microprudential supervision that only focused on the robustness of individual financial institutions to macroprudential supervision to prevent systemic financial risks. The financial system is regarded as a whole and the financial impact is studied. Internal interconnections and the links between the financial system and the macro economy have been studied.

This paper constructs a systemic financial crisis pressure index, uses the Granger causality method to select early warning indicators, and conducts an empirical study on systemic financial crisis early warning based on the dynamic Logit model. First, the financial crisis early warning is introduced, and the relevant literature on systemic financial risk measurement and systemic financial crisis early warning at home and abroad is reviewed; then, the main risk early warning models and the selection methods of early warning indicators and the selection methods of commonly used early warning indicators are introduced. We build financial systemic risk pressure indexes, including currency crisis pressure (EMP) index, banking crisis pressure (BCP) index, bubble crisis pressure (PBP) index, and external shock pressure (ESP) index to predict financial crises. There is mainly Granger causality analysis. After that, a systemic crisis pressure index and a systemic financial crisis early warning indicator system were constructed, and four indicators that had a significant impact on the systemic financial crisis pressure index were obtained using Granger causality analysis. Finally, an empirical study of the financial systemic risk early warning model, combined with the dynamic Logit model coefficients estimated from January 2010 to December 2018, predicts systemic financial crisis stress index in 2020 and gets the early warning signal curve of systemic financial crisis.

\section{Related Work}

The research of Wang et al. [4] also found that adding nonfinancial indicators can improve the accuracy of early warning. Domestic scholars' research on nonfinancial indicators is mainly divided into equity structure, company nature, controlling human type, corporate governance, industry factors, and corporate growth rate. In the use of financial early warning models, from the earliest univariate analysis to multivariate discriminant analysis, Logistic regression and Probit regression models were introduced into the financial distress early warning model. Since the 1990s, nonstatistical methods such as neural networks and support vector machines have been applied to the establishment of financial distress early warning models. In recent years, domestic and foreign scholars have continuously improved and updated the research modeling methods of corporate financial distress. Lin et al. [5] constructed the PSO-SVM model to select the optimal index set and conduct financial crisis early warning. Antunes et al. [6] proposed the use of fuzzy support vector machine (FSVM) algorithm to improve traditional SVM and obtained correct results. Tunay et al. [7] constructed a Partial Least-Squares Logistic model and conducted an empirical study on ST listed companies in stock markets. Misman and Bhatti [8] used multivariate discriminant analysis, Logistic regression, and neural network methods to establish a combined classifier model. Papadopoulos et al. [9] introduced a multifeature segmentation classifier model for financial distress early warning. Liu and Song [10] established an early warning model based on fuzzy C-means clustering and adaptive regression and proved through empirical research that the model is superior to discriminant analysis and forward neural network methods. Abdelsalam and Abdel-Latif [11] used data envelopment analysis to provide decision-makers with accurate prediction results. In addition, the study of financial distress early warning is continued through organic combinatorial mathematical methods [12] or continuous improvement of existing methods. The methods involved include case-based reasoning, combination of multiple classifiers, and genetic algorithms. In the selection of sample data, most of the financial early warning studies are based on cross-sectional data. Although cross-sectional data are easy to collect, the information content of the sample is limited and cannot reflect the company's data over multiple periods. Considering the limitations of static measurement and statistical models, a few scholars have established financial distress early warning models based on panel data. Mohana Rao and Padhi [13] used the panel data of the Athens Stock Exchange from 1993 to 2009 to establish a dynamic 
nonlinear model for financial early warning. Hlaing and Kakinaka [14] selected the unbalanced panel data of some A-share listed companies from 1997 to 2002, established the panel data Logo and Probit model, and obtained the degree of impact of the lagging financial data on the financial distress of listed companies through marginal analysis. Zhou et al. [15] found that the comprehensive recognition ability of the BP neural network model based on panel data for the 4 years before the financial crisis was over $75 \%$. Liu et al. [16] used time series discriminant analysis technology and indexweighted moving average control chart model to establish a multistage dynamic financial crisis early warning model and achieved good forecasting results. In recent years, more research results have been obtained in the comparison of financial early warning modeling methods and methods. Interdisciplinary methods such as neural networks, expected default rates, rough sets, support vector machines, and gray case reasoning are becoming more and more important. It has been applied more and more in the field of financial distress early warning research. From the perspective of sample data selection, not many people use the information advantages of panel data to establish a panel data model for financial distress warning and even less use the panel discrete selection model to conduct financial distress warning research. In addition, although some scholars have found significant differences in the financial ratios of different industries [17], no scholars have conducted comparative studies on the applicability of financial distress warning models in different industries.

Another aspect of crisis early warning system innovation is the construction of early warning indicator system or risk pressure index. The indicator system can be initially established from the perspectives of macro, financial system, and external shocks, and various methods can be used to optimize and screen indicators, such as Granger causal regression method, principal component analysis method, KLR signal analysis method, and univariate regression method; when constructing the risk pressure index, the description of financial crisis generally starts from the three perspectives of currency crisis, banking crisis, and asset bubble crisis. Therefore, the construction of the pressure index is also based on these three aspects. The corresponding indicators are selected to construct the systemic risk pressure index, respectively, and then representative indicators are selected for risk warning. This paper is based on the three aspects of the crisis pressure index constructed by the predecessors. The international shock risk pressure index is added, and through equal weight weighting technology, a systemic risk pressure index containing four pressure indexes is comprehensively formed. This approach can better warn of the new financial crisis at this stage. Research on the construction of early warning indicator system or risk pressure index: Li Liangqiong [18] established a commercial bank risk early warning indicator system from the perspectives of capital adequacy risk, credit risk, interest rate risk, profitability risk, and liquidity risk, used principal component analysis method, evaluated the risk status of commercial banks, used independent sample test to screen explanatory variables, and then established a BP neural network early warning model based on several key indicators. There are 23 early warning indicators selected from the four aspects of bubble risk and global economy, and the nonlinear MS-VAR model is applied to three submarket financial crisis pressure indexes, which are currency crisis pressure index, BCP index, and asset bubble crisis pressure index. On this basis, the factor analysis method was used to synthesize a financial vulnerability index that can reflect the status of the entire financial system, the SWARCH model was used to construct a financial crisis early warning model. It also warned of the overall financial risk in the second half of 2008. Nenu et al. [18] constructed a credit risk indicator system for commercial banks from six aspects, profitability indicators, growth indicators, liquidity and solvency indicators, asset management efficiency indicators, cash flow indicators, and market supervision indicators, used principal component analysis to filter indicators into Logit model, and conducted empirical quantitative management of the credit risk of commercial banks. According to the structural characteristics of representative financial indicators, Mirza et al. [19] constructed a time-sensitive financial stress index to identify the stress of financial system. The construction of pressure index adopts equal weight weighting method, which has certain reference significance for this paper. This paper applies nonfinancial indicators such as equity structure, ultimate controller type, and audit opinions to the panel discrete selection model to analyze the increase in early warning information of nonfinancial indicators. On this basis, it studies the impact of industry differences on the financial early warning model and empirical research on the financial distress early warning capability of the panel discrete choice model under different critical points.

\section{Financial Crisis Early Warning Mode}

3.1. Principle of Panel Discrete Selection Model. Panel data are the data obtained by a fixed group of survey objects continuously observed in multiple periods. It is the data with three-dimensional (cross section, period, and variable) information obtained at the same time in time and cross section, so it is also called time series and cross-section hybrid data. In actual economic problems, especially in microeconomic research, the variables to be explained may be discrete variables. In this case, you need to build a discrete selection model for the façade panel (DCM) [15]. If there are only two choices for the explained variable, such as financial distress and nonfinancial distress, a dual choice model can be established. Commonly used panel discrete selection models include panel Logit model and panel Probit model. Among them, the panel Probit model requires the random error term to obey the normal distribution, but the panel logo model does not have this requirement. Therefore, this paper adopts the panel logo model to model [16].

Binary choice models usually appear in the form of hidden variables. Take the panel binary selection model with 
only one explanatory variable with individual effects as an example; namely,

$$
y_{i j}=x_{i}+\lambda x_{i j}+\varepsilon_{i j}
$$

In the formula, $\varepsilon_{i j} \sim{ }^{i i} d N\left(0, \sigma^{2}\right)$, its probability distribution function is $F(\cdot)$, and $\varepsilon_{i j}$ is independent of the explanatory variable $x_{i j} ; x_{i}$ is the individual effect; $\hat{y}_{i j}$ is the observable binary choice variable $y_{i j}$ implicit variable.

When $\hat{y}_{i j}>0, y_{i j}=1$ can be observed; when $\widehat{y}_{i j} \leq 0$, $y_{i j}=0$. The probability that $y_{i j}=1$ takes a value of 1 is

$$
p_{i j}=\frac{e^{y_{i j}}}{e^{y i_{j}}+1} \text {. }
$$

The calculation shows that when $\hat{y}_{i j}>0$ and $p_{i j}=\left(e^{y_{i j}} /\left(e^{y i_{j}}+1\right)\right)>0.5$, it is judged that $y_{i j}=1$; when $\widehat{y}_{i j} \leq 0$ and $p_{i j}=\left(e^{y_{i j}} /\left(e^{y i_{j}}+1\right)\right) \leq 0.5$, it is judged that $y_{i j}=0$. That is, $\widehat{y}_{i j}$ is greater than or less than 0 to determine the value of $y_{i j}$, and the critical point used is 0.5 .

Combined with the research content of this paper, here it is assumed that the implicit variable $\widehat{y}_{i j}$ represents a state of company $i$ at time $j, x_{i j}$ represents the value of the index selected by company $i$ at time $j$, and $y_{i j}=1 ; y_{i j}=0$, which means that company $i$ has not been stopped in period $j$.

When the intercept term $u$ of individual heterogeneity is related to an explanatory variable, OLS estimation is no longer a consistent estimation, and a fixed-effect panel logo model should be established. When ui is uncorrelated with all explanatory variables, a random effect panel logo model should be established. The Hausman test is usually used to determine which effect should be selected. The null hypothesis of Hausman test is that the random effects model is the correct model [17]. At a certain level of significance, accepting the null hypothesis means that a random effects model should be selected; otherwise, a fixed effects model should be established. The research content and realization method of this paper are shown in Figure 1 .

\subsection{Construction of Financial Systemic Risk Stress Index.} The construction of the financial systemic risk pressure index in this paper is completed in two steps. First, according to the methods used by previous scholars to construct the currency crisis pressure index (CPI), BCP index, and BCP index, the ESP index is introduced. Second, after standardizing the four indexes, the weighted average of equal weight is used as the systemic financial crisis pressure index (SFCPI) in this paper. The early warning model in this paper uses the commonly used foreign exchange market pressure (EMP) index to measure whether a country has a currency crisis. The index measures the fluctuation range of the real exchange rate and the fluctuation range of foreign exchange reserves. The exchange rate market pressure index is calculated as follows:

$$
E=\frac{R_{t}-R_{t-1}}{R_{t-1}} w_{R}-\frac{r_{t}-r_{t-1}}{r_{t-1}} w_{r} .
$$

It is the weighted average of changes in the real exchange rate $(R)$ and changes in foreign exchange reserves $(r)$. Weights $w_{R}$ and $w_{r}$ are the relative accuracy of each variable. Variables with small volatility have a larger weight. The relative accuracy is determined by the reciprocal of the standard deviation of each variable. Use the exchange rate market pressure index to define a currency crisis (CR), that is, when the foreign EMP index exceeds the average foreign exchange market pressure index by two standard deviations or more [18].

$$
\mathrm{CR}= \begin{cases}0, & \text { otherwise, } \\ 1, & \text { if } E>\bar{E}+2 S E(E) .\end{cases}
$$

The purpose of this paper is to use the dual choice model to establish an early warning model of the financial system and predict the possibility of a crisis in the next six months. After considering the crisis, the financial system needs some adjustment time. It can be restored to a relatively stable state. At the same time, the crisis lag period of $i$ months is given. At the same time, the variable CR is transformed into a dummy variable $Y$, which is defined as

$$
Y= \begin{cases}1, & \text { if } \mathrm{CR}=1, \\ 0, & \text { otherwise }\end{cases}
$$

In order to better monitor the operation of the financial system, in this paper, on the basis of the definition of currency crisis, a number of four boundary values are added. The force index is within different critical value ranges. The financial system is at its corresponding alert level. There are four critical values, which are 0.75 standard deviations, 1.5 standard deviations, 2 standard deviations, and 3 standard deviations.

3.3. Model Selection. Use $Y$ to represent whether there is a crisis signal in the financial system. If there is a crisis signal, $Y=1$; if it does not appear, then $Y=0$. Assume that the value of $Y$ depends on another unobservable variable $U$. And there is a certain functional relationship between $U$ and the predictor variable $X$ we use, $U=g(x)$, assuming a linear form:

$$
U=\lambda x+\varepsilon
$$

The value of $U$ determines whether the crisis signal $Y$ appears. Suppose that when $U>0$, there is a crisis signal, namely, $Y=1$; when $U \leq 0$, there is no crisis signal, namely, $Y=0$. Therefore, the probability of the crisis signal $Y$ is

$$
\begin{array}{r}
P(Y=1)=P(U>0) \\
=P(\varepsilon>-x \lambda) .
\end{array}
$$

Assuming that $\varepsilon$ has a standard logistic distribution, the distribution function of $\varepsilon$ is $F(x)=e^{x} /\left(1+e^{x}\right)$. So you get the probability that the crisis signal $m$ appears as

$$
P(Y=1)=\frac{e^{x \lambda}}{1+e^{x \lambda}} .
$$




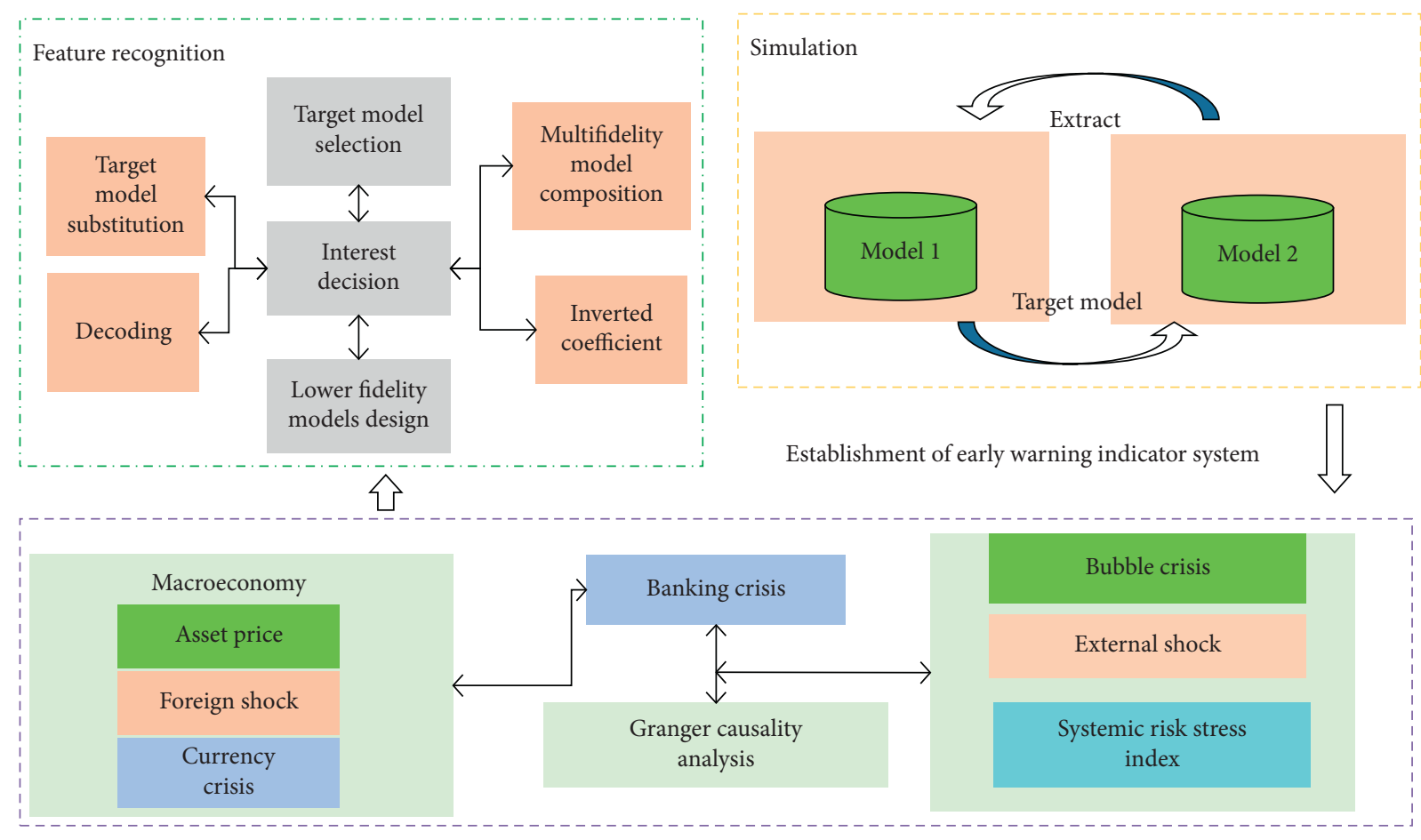

Figure 1: The discrete selection model.

This paper uses a set of independent variables $X$ to explain the crisis index $Y$; $X$ is the $K \times N$ matrix of observations. The Logit model in the aforementioned binary choice model is used to establish a crisis warning model. And use econometrics software (Eviews) for empirical analysis.

3.4. Index Selection. We have established China's financial risk monitoring index system from $i$ levels, including macroprudential indicators. This is the stability subsystem that reflects the macroeconomic environment. Market prudential indicators reflect market risks. Microprudential indicators reflect the internal stability subsystem of financial institutions. In the actual early warning system, the introduction of a large number of risk indicators can provide a comprehensive understanding of risk factors at all levels of the financial system. However, introducing too many indicators may increase the difficulty of model building. Moreover, the statistical indicator system has yet to be improved. Many economic and financial indicators cannot obtain complete or accurate data. Moreover, exchange rates and interest rates are mainly regulated by the government. The panel discrete selection model is shown in Figure 2.

\section{Empirical Research Based on the Dynamic Logit Early Warning Model}

4.1. Empirical Analysis of Logit Model. At the 5\% significant level, the four indicators that have Granger reasons for the systemic risk pressure index are the rate of change in the stock price (SP) index, the growth rate of industrial value added (IS), the actual domestic and foreign deposit interest rate differential (DI), and foreign investors direct investment as a percentage of GDP (DS). The empirical analysis results of static Logit and dynamic Logit models are as follows.

From the results of the model estimation in Figure 3, the Granger index of FDI in GDP and the growth rate of industrial added value are the most significant, and the former coefficient is positive, indicating that the increase in the proportion of foreign direct investment in GDP will increase the probability of a systemic financial crisis; the latter coefficient is negative, indicating that the increase in the growth rate of industrial value added is beneficial to preventing the outbreak of a systemic financial crisis. The significance of the domestic and foreign real deposit interest rate differential is weak, and the coefficient is negative, indicating that when the domestic real deposit interest rate is lower than the US real deposit interest rate, as the interest rate differential increases, the possibility of a systemic financial crisis is less.

The stock index change rate is negative in the static Logit model and positive in the dynamic Logit model, but both are not significant. The coefficient of the lagging binary dynamic term is positive, and the null hypothesis is rejected at the $5 \%$ significance level, indicating that it is necessary to introduce the lagging binary dynamic term into the Logit model. It indicates that once a systemic financial crisis occurs, it will have a positive impact on the outbreak of a systemic financial crisis again within a period of time.

We further analyze the accuracy of the model. According to the AIC criterion and SC criterion, it is concluded that the first-order lag of the binary dynamic term is correct; according to the maximum likelihood value estimated by the model, the dynamic Logit model is better than the static Logit model. We set Logit model as the benchmark model. In order to compare the fitting effects of the two models more 


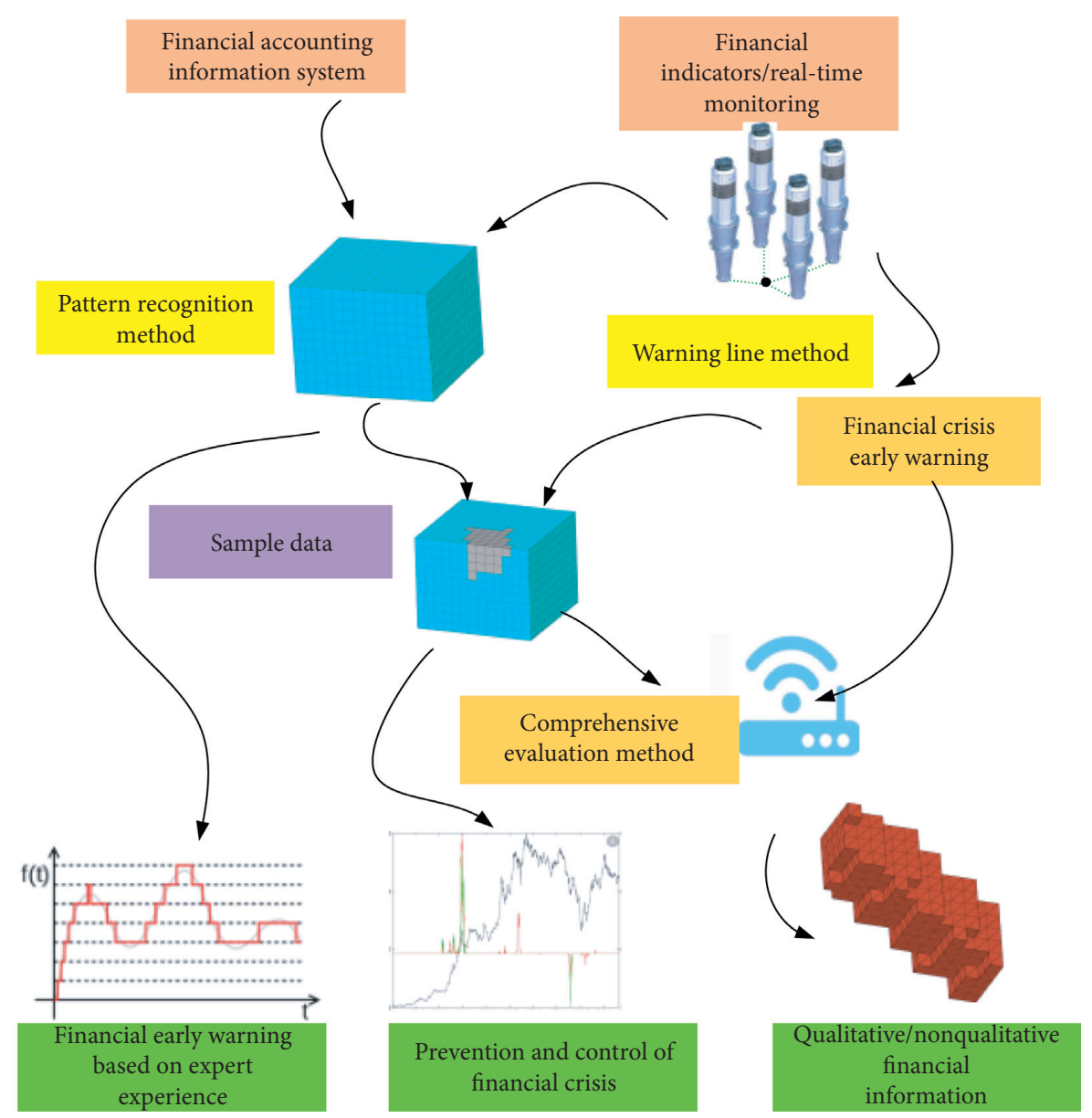

Figure 2: Panel discrete selection model.

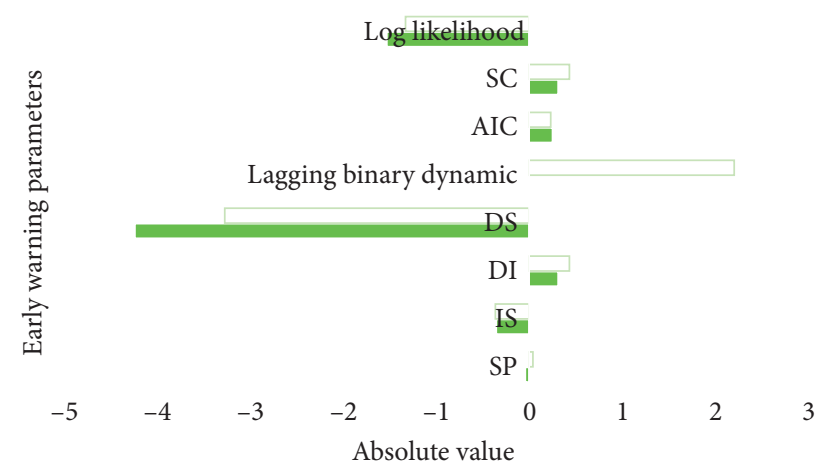

Dynamic logit model

- Static logit model

FIGURE 3: Estimation results of the early warning model.

accurately, the static Logit model and the dynamic Logit model are, respectively, predicted-expected analysis based on the predicted cutoff value equal to 0.5 , and the results in Figures 4 and 5 are obtained.

The purpose of expectation analysis is mainly to reflect the appropriateness of the grouping of observations, when the predicted probability is less than or equal to the cutoff value and the observation value is equal to. Or when the predicted probability is greater than the cutoff value and the observation value is equal to 1 , the model grouping is appropriate; otherwise, the grouping is not appropriate. The proportion of the appropriate number to the total number of samples is the appropriate rate. The higher the appropriate rate, the better the model grouping. The cutoff value selected in this paper is 0.5 . According to the static Logit model in Figure 4, the expected analysis results show that the 


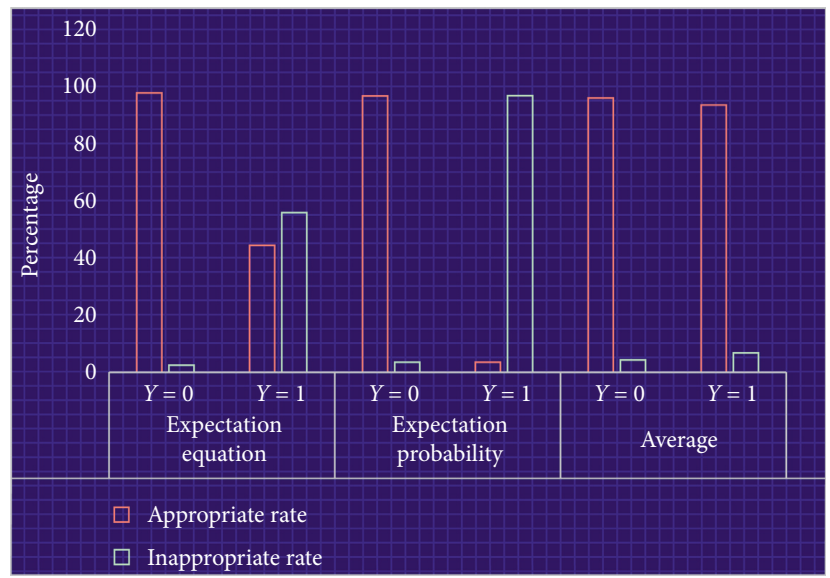

FIGURE 4: Forecast-expectation analysis of early warning indicators of static model.

appropriateness rates of grouping are $97.87 \%$ and $95.48 \%$ (predicted results calculated based on the expected value); and the dynamic Logit model is shown in Figure 5. In the prediction-expectation analysis result, the grouping appropriateness rate reached $97.93 \%$ and $96.06 \%$ (predicted results calculated based on the expected value). Based on the above analysis, the fitting effect of the dynamic Logit model with lagging binary variables is better than the static Logit model.

\subsection{Dynamic Logit Model Prediction Effect Evaluation.} We use four early warning indicators from January 2010 to December 2018, which are the rate of change in the stock price index, the growth rate of industrial value added, the difference between domestic and foreign real deposit interest rates, and the monthly data on the percentage of foreign direct investment in GDP.

The data are substituted into the dynamic Logit model, and the estimated coefficients and descriptive statistics of each indicator are shown in Figure 6.

\section{Financial Crisis Early Warning Forecasts Results}

The differential autoregressive moving average model is generally expressed as ARIMA $(p, d, q)$, where $\mathrm{AR}$ is autoregressive and MA is moving average; $p$ and $q$ are the number of autoregressive terms and moving average terms; and $d$ is the conversion of the original time series. The difference required for a stable time series is formed. In view of the accuracy of the ARIMA model, it has gradually become one of the common methods for short-term forecasting in the field of economic forecasting in recent years. Mancino and Sanfelici [20] showed that when forecasting stock index futures prices using the ARIMA model, the results show that the short-term prediction effect of the ARIMA model is good and can effectively reflect the volatility trend of futures prices; Rao and Padhi [21] used SAS software to analyze the specific algorithm of the AR industrial MA model and built a multiplicative AR industrial MA model to predict and analyze the basic trend of $\mathrm{CP}$

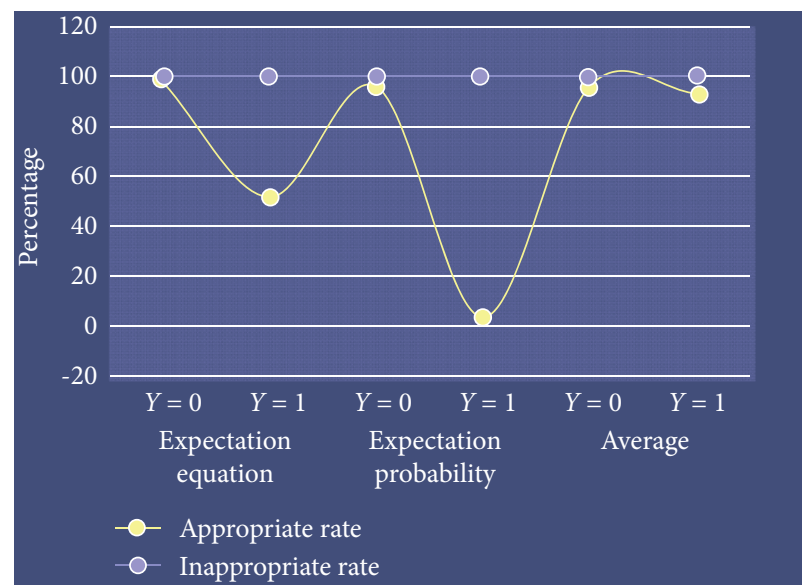

FIGURE 5: Forecast-expectation analysis of early warning indicators of dynamic model.

workers; Fong et al. [22] also used the AR industrial MA model to make short-term forecasts on different economic indicators, and both showed good predictions.

Based on the ARIMA model forecast, this paper obtains the monthly data of the proportion of foreign direct investment in GDP, the domestic and foreign real deposit interest rate difference, and the growth rate of industrial value added in 2020, respectively, as shown in Figures 7-9.

From the perspective of domestic economic operation, in 2013, China continued to implement a proactive fiscal policy and a prudent monetary policy, placing steady growth in a more important position. The economic policy model has gradually shifted from an export-oriented economy to an autonomous economy that expands domestic demand. A series of measures to benefit the people have been introduced, such as increasing the protection of low-income groups and encouraging and driving the development of private investment. In addition, the improvement of the international situation has effectively alleviated the contradiction between supply and demand in the process of domestic economic slowdown, and the overall inflationary pressure is relatively small. The improvement of the global economic situation provides a stable external environment 


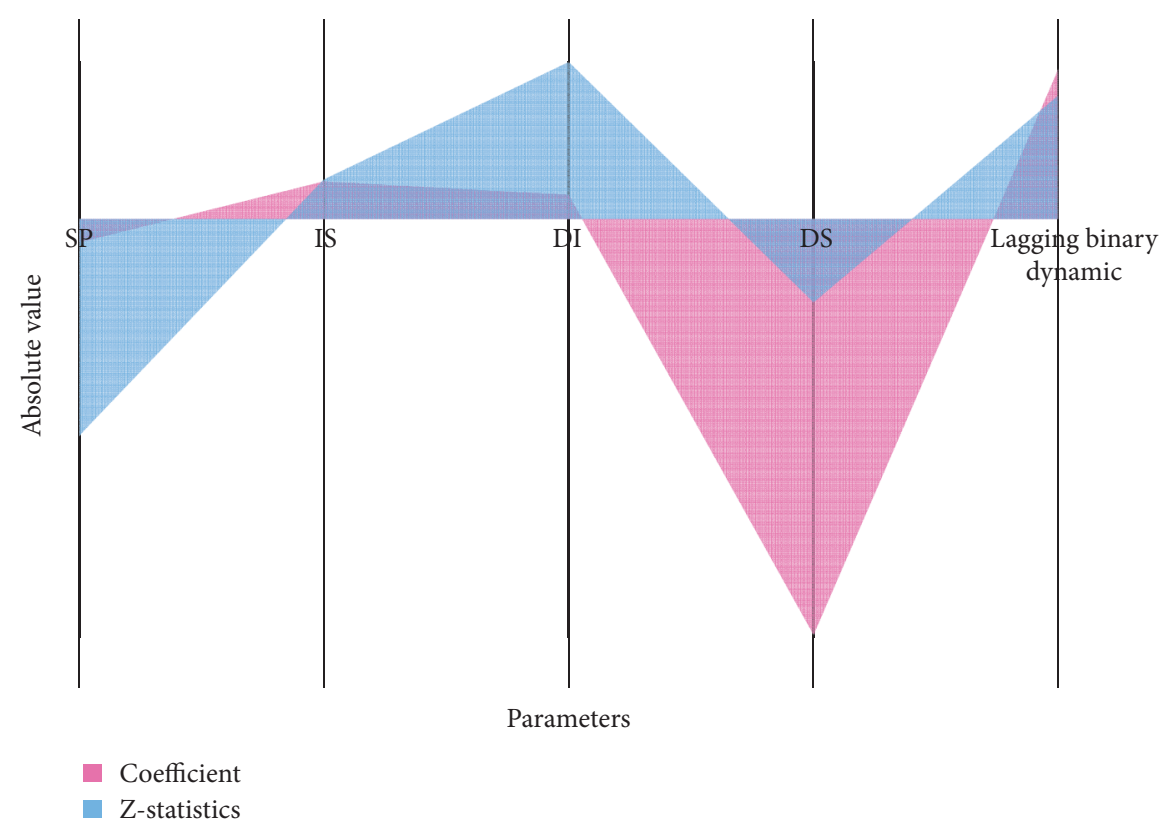

FIGURE 6: Dynamic Logit model estimation results.

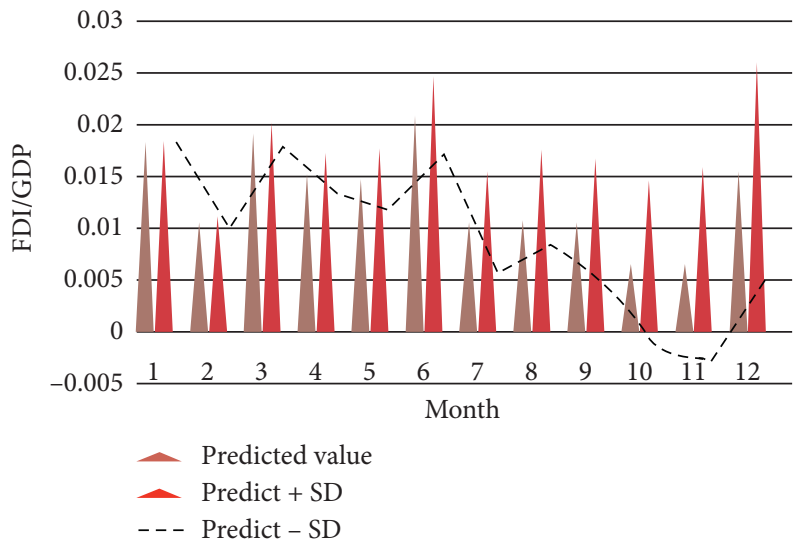

FIGURE 7: $2020 \mathrm{FDI} / \mathrm{GDP}$ forecast data.

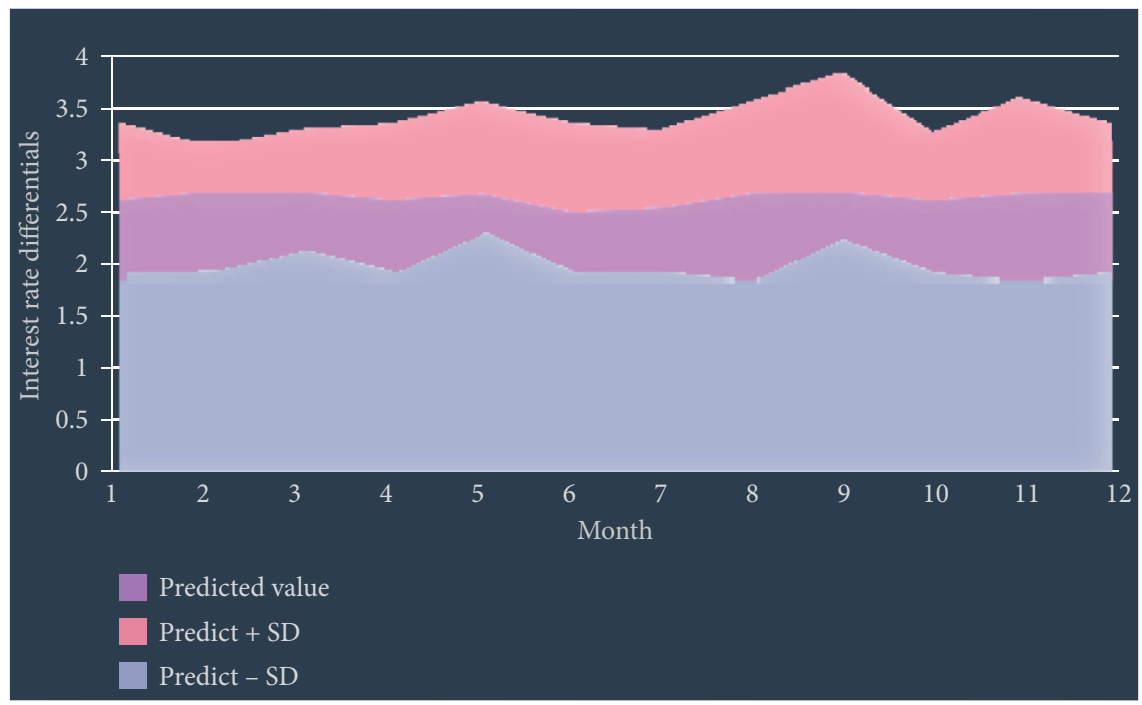

FIgURE 8: 2020 forecast data of domestic and foreign real deposit interest rate differentials. 


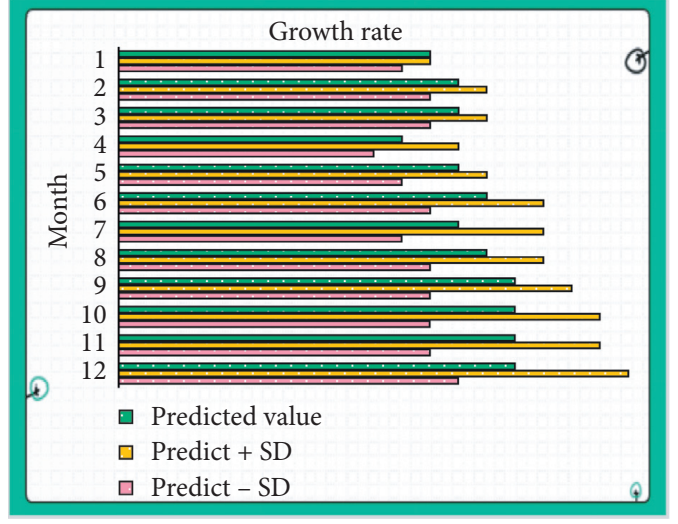

FIGURE 9: Forecast data of industrial added value growth rate in 2020 .

for China's economic development. The implementation of the domestic proactive fiscal policy and prudent monetary policy has strengthened the stability of China's financial system, and its ability to withstand external shocks has also been correspondingly improved.

\section{Conclusion}

This paper uses the Logit model to establish China's crisis early warning system and draws the following conclusions: the Logit model is conducive to analyzing the relationship between crisis events, a certain variable, and various influencing factors. We use various methods to verify the experimental results, such as Granger causal regression, principal component analysis, KLR signal analysis, and univariate regression. The macroeconomic indicators, balance of payments indicators, and microfinancial institution indicators are used in this paper. It has a certain early warning effect on crises. This paper examines the actual effect of the Logit model in the process of crisis warning and uses the ARIMA model to make short-term forecasts for various crisis warning indicators. The out-of-sample prediction of the Logit model is realized. This improves the actual role of the crisis early warning model in the financial crisis early warning process. This paper's research on systemic financial crisis early warning mainly starts from the perspective of empirical analysis. Based on the currency crisis pressure index, $\mathrm{BCP}$ index, asset bubble crisis pressure index, and ESP index, a SFCPI is synthesized. The four aspects of economy, financial system, asset prices, and foreign shocks construct an early warning indicator system for systemic financial crisis, use Granger causality analysis to screen early warning indicators, construct a dynamic Logit model with lagging binary variables, and compare it with static Logit. The model uses the ARIMA model for shortterm forecasting of economic indicators in the empirical simulation of systemic financial crisis early warning and uses the dynamic Logit model to simulate the performance of the early warning of systemic financial crisis in 2020. In the current situation of close global economic ties, the research results of this paper provide a certain reference for China to build a systemic financial crisis early warning system and effectively prevent systemic financial crises and have very important practical significance.

\section{Data Availability}

The data used to support the findings of this study are available from the corresponding author upon request.

\section{Conflicts of Interest}

The authors declare that they have no known competing financial interests or personal relationships that could have appeared to influence the work reported in this paper.

\section{References}

[1] A. Samitas, E. Kampouris, and D. Kenourgios, "Machine learning as an early warning system to predict financial crisis," International Review of Financial Analysis, vol. 71, p. 101507, 2020.

[2] R. Padhan and K. P. Prabheesh, "Effectiveness of early warning models: a critical review and new agenda for future direction," Buletin Ekonomi Moneter Dan Perbankan, vol. 22, no. 4, pp. 457-484, 2019.

[3] B. Ioan, R. Malar Kumaran, B. Larissa et al., "A panel data analysis on sustainable economic growth in India, Brazil, and Romania," Journal of Risk and Financial Management, vol. 13, no. 8, pp. 17-20, 2020.

[4] T. Wang, S. Zhao, G. Zhu, and H. Zheng, "A machine learning-based early warning system for systemic banking crises," Applied Economics, vol. 1, no. 7, pp. 1-19, 2021.

[5] W. L. Lin, J. A. Ho, and M. Sambasivan, "Impact of corporate political activity on the relationship between corporate social responsibility and financial performance: a dynamic panel data approach," Sustainability, vol. 11, no. 1, pp. 6-10, 2019.

[6] A. Antunes, D. Bonfim, N. Monteiro, and P. M. M. Rodrigues, "Forecasting banking crises with dynamic panel probit models," International Journal of Forecasting, vol. 34 , no. 2, pp. 249-275, 2018.

[7] K. B. Tunay, H. F. Yüceyılmaz, and A. Çilesiz, "In emerging economies, the effect of excessive credit growth and nonperforming loans on banking crisis," Contaduría $Y$ Administración.vol. 65, no. 1, pp. 1-5, 2020.

[8] F. N. Misman and M. I. Bhatti, "The determinants of credit risk: an evidence from ASEAN and GCC Islamic Banks," Journal of Risk and Financial Management, vol. 13, no. 5, pp. 89-90, 2020.

[9] S. Papadopoulos, P. Stavroulias, and T. Sager, "Systemic early warning systems for EU14 based on the 2008 crisis: proposed estimation and model assessment for classification forecasting," Journal of Banking Regulation, vol. 20, no. 3, pp. 226-244, 2019.

[10] H. Liu and Y. Song, "Financial development and carbon emissions in China since the recent world financial crisis: evidence from a spatial-temporal analysis and a spatial Durbin model," Science of the Total Environment, vol. 715, p. 136771, 2020.

[11] M. A. M. Abdelsalam and H. Abdel-Latif, "An optimal early warning system for currency crises under model uncertainty," Central Bank Review, vol. 20, no. 3, pp. 99-107, 2020.

[12] D.-E. Rhee and H. Kim, "Does income inequality lead to banking crises in developing countries? Empirical evidence 
from cross-country panel data," Economic Systems, vol. 42, no. 2, pp. 206-218, 2018.

[13] B. Mohana Rao and P. Padhi, "Identifying the early warnings of currency crisis in India," Foreign Trade Review, vol. 54, no. 4, pp. 269-299, 2019.

[14] S. W. Hlaing and M. Kakinaka, "Financial crisis and financial policy reform: crisis origins and policy dimensions," European Journal of Political Economy, vol. 55, no. 5, pp. 224-243, 2018.

[15] Y. Zhou, J. Fu, Y. Kong, and R. Wu, "How foreign direct investment influences carbon emissions, based on the empirical analysis of Chinese urban data," Sustainability, vol. 10, no. 7, p. 2163, 2018.

[16] J. Liu, J. Tang, B. Zhou, and Z. Liang, "The effect of governance quality on economic growth: based on China's provincial panel data," Economies, vol. 6, no. 4, pp. 56-58, 2018.

[17] W. Li and T. Adachi, "Quantitative estimation of resource nationalism by binary choice logit model for panel data," Resources Policy, vol. 53, pp. 247-258, 2017.

[18] E. Nenu, G. Vintilă, and Ş. Gherghina, "The impact of capital structure on risk and firm performance: empirical evidence for the Bucharest Stock Exchange listed companies," International Journal of Financial Studies, vol. 6, no. 2, pp. 41-44, 2018.

[19] S. S. Mirza, T. Ahsan, R. Safdar, and A. U. Rehman, "Competition, debt maturity, and adjustment speed in China: a dynamic fractional estimation approach," Journal of Risk and Financial Management, vol. 13, no. 5, pp. 106-108, 2020.

[20] M. E. Mancino and S. Sanfelici, "Identifying financial instability conditions using high frequency data," Journal of Economic Interaction and Coordination, vol. 15, no. 1, pp. 221-242, 2020.

[21] B. M. Rao and P. Padhi, "Common determinants of the likelihood of currency crises in BRICS," Global Business Review, vol. 21, no. 3, pp. 698-712, 2020.

[22] T. P. W. Fong, A. K. W. Sze, and E. H. C. Ho, "Determinants of equity mutual fund flows-evidence from the fund flow dynamics between Hong Kong and global markets," Journal of International Financial Markets, Institutions and Money, vol. 57, pp. 231-247, 2018. 